\title{
Laparoscopic Management of Hepatic Hydatid Disease - Results From a Developing World Country
}

\author{
Authors \\ Dr Zahida Akhter, Prof. Farooq Ahmad Reshi, Prof. Iqbal Saleem Mir, \\ Dr Tanveer Ahmad Yatoo, Dr Abdul Rashid Ganaie, Dr Zaheem, Dr Aftab Akbar, \\ Dr Yaqoob, Dr Yasir Rehman \\ Post Graduate Department of General Surgery \\ Government Medical College, Srinagar
}

\section{Introduction}

Hydatid disease is one of the major health problem in the infested areas of world, mainly in sheep-raising areas like North Africa, Turkey, the Middle East, Australia, New Zealand, South America, Baltic areas, the Philippines, Northern China, and the Indian subcontinent. However it can be found anywhere, in the world owing to increased travel and tourism as the world has shrunken to a global village. ${ }^{1}$

Hepatic hydatidosis is caused by the parasite, Echinococcus granulosus, Echinococcus has intermediate and definitive hosts. Canidae, especially dogs, are the definitive hosts; ruminants may also host the organism. Sheep and goats are intermediate hosts, although E. granulosus can also be hosted by a wide range of vertebrates. Man is the accidental intermediate host. ${ }^{2}$

The most common site of occurrence of hydatid cysts in humans is the liver $(50 \% \text { to } 93 \%)^{3}$ followed by lungs. The typical lesion is a cystic cavity filled with clear hydatid fluid containing live protoscoleces.

The rationale for elective treatment of hydatid lesionof liver is based on the possibility that it may grow and cause symptoms and complications such as infection, jaundice or cholangitis from biliary communication, rupture and anaphylaxis. Treatment of hepatic hydatid of the liver can include medical therapy, percutaneous drainage, or surgical intervention (via a conventional or laparoscopic approach).

The aims of surgery are complete evacuation of cyst without spillage, followed by sterilization and obliteration of the cavity. Laparoscopic approach is a suitable surgical technique to achieve these aims, but there are certain technical problems to overcome. In particular, intraparanchymal cysts, which do not reach the surface of the liver, are difficult to localize and manage laparoscopically. Multiplicity and location of the cysts are the other two parameters to be considered while planning treatment.

The aim of this study was to determine the results of the laparoscopic management of hepatic hydatid cyst disease from a developing world country. 


\section{Material and Methods}

A prospective study conducted in the Department of General Surgery, Government Medical College, Srinagar over a period of 3 years. 38 patients underwent laparoscopic procedure for hydatid cyst. Most common symptom was upper abdominal pain. Diagnosis was established on the basis of clinical examination, serology, abdominal ultrasonography and computed tomography.

Exclusion criteria for laparoscopic surgery were:

1) If deemed unfit for laparoscopy

2) Previous multiple upper abdominal surgeries likely to have adhesions;

3) Cysts located more than $1 \mathrm{~cm}$ deep from the liver surface, which may prove difficult to identify laparoscopiacally.

4) Infected hydatid cyst.

5) Multiple liver hydatid cysts or cyst located near vascular liver element, and those located in segment 1,8 and 7 as they are considered in blind areas for laparoscopic procedure.

6) Cyst other than CL, CE - 1,2,3 according to World Health Organization (WHO) Classification.

7) Patient's operated in emergency for ruptured hydatid were also excluded.

All patients were treated with Albendazole (dose $15 \mathrm{mg} / \mathrm{kg}$ ) for three weeks prior to surgery.

All procedures were performed under general anesthesia. Injection ceftriaxone $1 \mathrm{~g}$ was given before induction of anesthesia. All Patients received injection Hydrocortisone prophylactically before surgery. After creating pneumoperitonium a 30 degree telescope was introduced via umbilical port. A $10 \mathrm{~mm}$ port at epigastrium was used as a working port and a third port $5 \mathrm{~mm}$ was inserted for mobilization and access, position depending on the location of the cyst in liver. Operating field was isolated by surrounding the cyst with gauzes soaked in Betadine $10 \%$ solution. The cyst fluid was evacuated using an aspirating needle and color of the fluid noted. A continuous suction cannula was kept around the needle puncture site. Scolicidal agent ( $10 \%$ betadine) was injected in to the cyst and aspirated after 10 minutes using suction followed by unroofing of the cyst wall. A $10 \mathrm{~mm}$ sucker was introduced and all the cyst contents were thoroughly evacuated and irrigated with hypertonic saline. The cavity was examined for any remaining contents, daughter cysts and biliary leak. Biliary community were closed using 3'0 silk suture. Omentum was placed in residual cavity. A drainage tube was introduced into the cysts cavity for postoperative drainage. Gauze and pieces of excised cyst wall were placed in an endo sac and removed without spillage. Orals were started on first postoperative day. Albendazole was started on $2^{\text {nd }}$ postoperative day in all patients. Drain was removed on $2^{\text {nd }}$ postoperative day if no bile leakage occurred. Patients were discharged on $3^{\text {rd }}$ to $4^{\text {th }}$ postoperative day. The cyst cavity was monitored post-operatively by ultrasound at 2 weeks, 1, 3 and 6 months interval.

\section{Results}

Thirty eight patients underwent laparoscopic management of hepatic hydatid cyst. Mean age of presentation was 34.8 years (range 11to 68 year).There were $28(73.68 \%)$ female patients and $10(26.31 \%)$ male patients. Most common presenting symptom was pain upper abdomen in32 $(84.21 \%)$ patients followed by mass abdomen in $2(5.26 \%)$ patients, incidental finding in $4(10.52 \%)$ patients.

Average size of cysts was $8.4 \mathrm{cms}$ with range of 5 to 14 cmonly single cyst was present in $7(18.42 \%)$ patients, two cysts in26 (68.42\%) patients and three cysts in $5(13.15 \%)$ patients. Cysts were present in Right lobe of liver in $30(78.94 \%)$ in left lobe2 $(5.26 \%)$ in both lobes $6(15.78 \%)$ patients.

Operative time ranged from $90 \mathrm{~min}$ to $120 \mathrm{~min}$ with zero conversion rate. Mean hospital stay was 4.46 days. No patient had anaphylactic shock or peritonitis. Postoperative chest infection was present in $3(7.89 \%)$ patients. Intraoperative cystobiliary communication was detected in 2(5.26\%) patients which was closed using 3-0 silk 
suture. Minor bile leak was present in $4(10.52 \%)$ of patients which was managed conservatively. Persistent bile leakage beyond 6 weeks was present in $1(2.63 \%)$ patient which was managed by ERCP and papillotomy. Recurrence of hydatid cyst was observed in $3(7.89 \%)$ of patients. There was no mortality in our study group.

\begin{tabular}{|l|c|c|}
\hline \multicolumn{2}{|l|}{ Patient Characteristics } \\
\hline \multirow{2}{*}{ Gender (n=38) } & Male & $10(26.3 \%)$ \\
\cline { 2 - 3 } & Female & $28(73.68 \%)$ \\
\hline Mean age(Years) & Abdominal pain & 32.8 years \\
\hline \multirow{3}{*}{$\begin{array}{l}\text { Presenting } \\
\text { complaints }\end{array}$} & Abdominal mass & $2(5.26 \%)$ \\
\cline { 2 - 3 } & $\begin{array}{c}\text { Incidental finding } \\
\text { (USG) }\end{array}$ & $4(10.52 \%)$ \\
\hline Average size of cyst (cm) & $8.4 \mathrm{~cm}$ \\
\hline \multirow{4}{*}{ Number of cysts } & Single cyst & $7(18.42 \%)$ \\
\cline { 2 - 3 } & Two cysts & $26(68.42 \%)$ \\
\cline { 2 - 3 } & Multiple cysts & $5(13.15 \%)$ \\
\hline \multirow{3}{*}{\begin{tabular}{l} 
Location of cysts \\
\cline { 2 - 3 }
\end{tabular}} & Right lobe & $30(78.94 \%)$ \\
\cline { 2 - 3 } & Left lobe & $2(5.26 \%)$ \\
\cline { 2 - 3 } & Bilateral & $6(15.78 \%)$ \\
\hline
\end{tabular}

\begin{tabular}{|c|c|c|}
\hline \multicolumn{3}{|l|}{ Outcome } \\
\hline \multicolumn{2}{|c|}{ Operative time (min) } & $90-120 \mathrm{~min}$ \\
\hline \multicolumn{2}{|c|}{$\begin{array}{ll}\text { Intraoperative } & \text { cystobiliary } \\
\text { communication } & \end{array}$} & $2(5.26 \%)$ \\
\hline \multicolumn{2}{|l|}{ Conversion rate } & $0(0 \%)$ \\
\hline \multicolumn{2}{|c|}{ Mean hospital stay } & 4.46 days \\
\hline \multirow{5}{*}{$\begin{array}{l}\text { Postoperative } \\
\text { complications }\end{array}$} & Anaphylaxis & $0(0 \%)$ \\
\hline & Peritonitis & $0(0 \%)$ \\
\hline & Chest infection & $3(7.89 \%)$ \\
\hline & Minor bile leak & $4(10.52 \%)$ \\
\hline & Persistent bile leak & $1(2.63 \%)$ \\
\hline \multicolumn{2}{|c|}{ Recurrence of hydatid cyst } & $3(7.89 \%)$ \\
\hline
\end{tabular}

\section{Discussion}

Parasitic zoonoses is burden for public health, particularly in developing countries. It sporadically due to increased travel and migration ${ }^{4}$. Though the common mode of infection is the unhygienic practice of consuming unwashed or improperly washed infected raw fruits and vegetables, direct contact with infected $\operatorname{dogs}$ is also source of contracting the disease ${ }^{5}$.Youngest patient in our study was 11 years old with an average age of 34.8 years, likely showing a rising trend towards younger age group in Kashmir. In non endemic areas, all the age groups are equally affected with an average age of presentation being older ${ }^{6,7}$. Females were predominantly affected in the study (73.68\%).
Other published studies have also reported female preponderance $^{7,8}$. Abdominal pain was the most common mode of presentation (84.21\% of cases) in this study ${ }^{7,8}$. Hepatic hydatid cyst should be suspected in patients presenting with abdominal mass, pain, fever or jaundice; however, in nonendemic areas most of the cases are asymptomatic and are detected incidentally ${ }^{9,10}$. Majority of patients were having more than one cyst and right lobe of liver was commonly involved (in 78.94\%). Surgery is the mainstay of treatment for hepatic hydatid cysts. Laparoscopic treatment of hepatic disease was first reported in $1994^{10}$. It has gained popularity in the last decade with encouraging preliminary results; however, reports concerning long-term results of this technique are limited ${ }^{11}$. The common reasons to avoid laparoscopic surgery depend on spillage of cyst contents into abdominal cavity with fear of anaphylaxis and recurrence $^{12,13}$.

Reports started appearing in the world literature detailing laparoscopic management of liver hydatid disease $\mathrm{e}^{14-19,21-24}$. The indications, contraindications advantages, and disadvantages of this technique have been elucidated ${ }^{25,26}$.

\section{Conclusion}

Laparoscopic surgery of hepatic hydatid cysts is a safe and effective treatment in properly selected patients. It is a simple technique with potentially low risk of intra-abdominal spillage, lesser complications and recurrence with benefits of minimally invasive approach.

\section{Bibliography}

1. C. Palanivelu, Kalpesh Jani, Vijaykumar Malladi, R. Senthilkumar, P. S. Rajan, K. Sendhilkumar, et al. Laparosocpic management of hepatic hydatid disease. JSLS. 2006;10:56-62.

2. Joshi DD, Joshi AB, Joshi $H$. Epidemiology of echinococcosis in Nepal. Southeast Asian J Trop Med Public Health 1997; 28 Suppl 1:26-31. 
3. Huizinga WKJ, Grant CS, Daar AS. Hydatid disease. In: Morris PJ, Wood WC, eds. Oxford Textbook of Surgery. 2nd ed. New York, NY: Oxford University Press; 2000: 3298-3305.

4. Huizinga WKJ, Grant CS, Daar AS. Hydatid disease. In: Morris PJ, Wood WC, eds. Oxford Textbook of Surgery. 2nd ed. New York, NY: Oxford University Press; 2000;3298-3305.

5. Barnes SA, Lillemoe KD. Liver abscess and hydatid cyst disease. In: Zinner MJ, Schwartz SI, Ellis H, eds. Maingot's Abdominal Operations. 10th ed. Stamford, CT: Appleton \& Lange, 1997;1534-1545.

6. Cohen H, Paolillo E, Bonifacino R, Botta B, Parada L, Cabrera P, et al. Human cystic echinococcosis in a Uruguayan community: a sonographic, serologic, and epidemiologic study. Am J Trop Med Hyg. 1998;59(4):620-7.

7. Niscigorska J, Sluzar T, Marczewska M, Karpińska E, Boroń-Kaczmarska A, Morańska I, et al. Parasitic cysts of the liver: practical approach to diagnosis and differentiation. Med Sci Monit. 2001;7(4): 737-41.

8. Chautems R, Buhler L, Gold B, Chilcott M, Morel P, Mentha G. Long term results after complete or incomplete surgical resection of liver hydatid disease. Swiss Med Wkly. 2003;133:258-62.

9. Huizinga WK, Grant CS, Daar AS. Hydatid disease. In: Morris PJ, Wood WC, editors. Oxford textbook of surgery. 2nd ed. New York: Oxford University Press; 2000. p. 3298-305.

10. Palnivelu C, Jani K, Malladi V, Senthilkumar R, Rajan PS, Sendhilkumar $\mathrm{K}$, et al. Laparoscopic management of hepatic hydatid disease. JSLS 2006; 10:5662.

11. Ertem M, Karahasanoglu T, Yavuz N, Erguney S. Laparoscopically treated liver hydatid cysts. Arch Surg. 2002; 137:11703

12. Khoury G, Jabbour-Khoury S, Soueidi A, Nabbout G, Baraka A. Anaphylactic shock complicating laparoscopic treatment of hydatid cysts of the liver. SurgEndosc. 1998;12(5):452-4.

13. Yaghan R, Heis H, Bani-Hani K, Matalka I, Shatanawi N, Gharaibeh K, et al. Is fear of anaphylactic shock discouraging surgeons from more widely adopting percutaneous and laparoscopic techniques in the treatment of liver hydatid cyst? Am J Surg. 2004;187(4):533-7.

14. Guibert L, Gayral F. Laparoscopic pericystectomy of a liver hydatid cyst. Surg Endosc. 1995;9:442- 443.

15. Sever M, Skapin S. Laparoscopic pericystectomy of liver hydatid cyst. Surg Endosc. 1995;9:1125-1126.

16. Bickel A, Eitan A. The use of a large transparent cannula,with a beveled tip, for safe laparoscopic management of hydatidcysts of liver. SurgEndosc. 1995;9:1304-1305.

17. Khoury G, Jabbour-Khoury S, Bikhazi K. Results of laparoscopic treatment of hydatid cysts of the liver. SurgEndosc.1996;10:57-59.

18. Bickel A, Daud G, Urbach D, et al. Laparoscopic approach to hydatid liver cysts. Is it logical? Physical, experimental, and practical aspects. Surg Endosc. 1998;12:1073-1077.

19. Ertem M, Uras C, Karahasanoglu T, et al. Laparoscopic approachto hepatic hydatid disease. Dig Surg. 1998;15:333-336.

20. Verma GR, Bose SM. Laparoscopic treatment of hepatic hydatid cyst. Surg Laparosc Endosc. 1998;8:280 -282.

21. Massoud WZ. Laparoscopic excision of a single hepatichydatid cyst. Int Surg. 1996;81(1):9-13.

22. Khoury G, Geagea T, Hajj A, et al. Laparoscopic treatment ofhydatid cysts of 
the liver. Surg Endosc. 1994;8(9):11031104.

23. Emelianov SI, Khamidov MA. Laparoscopic treatment ofhydatid liver cysts. Khirurgiia (Mosk). 2000;(11):3234.

24. Manterola C, Fernandez O, Munoz S. Laparoscopic pericystectom yfor liver hydatid cysts. Surg Endosc. 2002;16(3):521-524.

25. Sayek I, Cakmakei M. Laparoscopic management of echinococcalcysts of the liver. Zentralbl Chir. 1999;124(12):11431146.

26. Katkhouda N, Trussler A. Laparoscopic surgery of the liver.In: Zucker KA, ed. Surgical Laparoscopy. 2nd ed. Philadelphia, PA: Lippincott Williams \& Wilkins; 2001;211-220. 